\title{
Assessing health related quality of life of school aged Saudi children in western province using the validated Arabic version of child health questionaire-parent form-50
}

Shatha M. Albokhari, MBBS, Wallaa A. Garout, MBBS, Maha M. Al-Ghamdi, MBBS, Alyaa A. Garout, MBBS

Sundus M. W. Noorsaeed, MBBS, Shahad M. Daali, MBBS.

\begin{abstract}

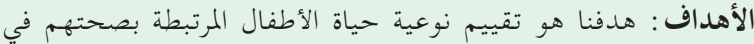

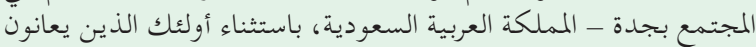
من أمراض مزمنة معروفة .

المنهجية : شاركت 4 مدارس في جدة في في هذه الدراسة المستعرضة ، التي

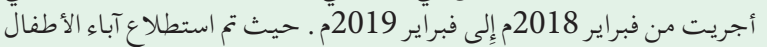

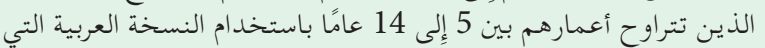

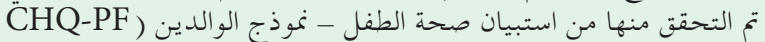

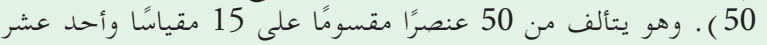

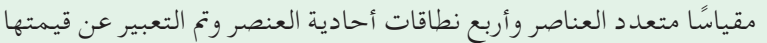

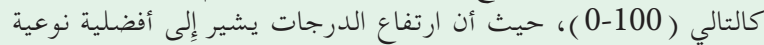

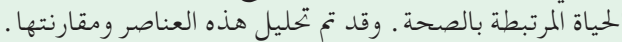

النتائج : أجاب آباء 498 طفلاً على الاستبيان . كانت متوسطات النقاط

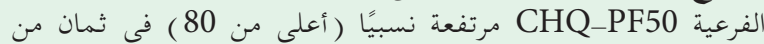

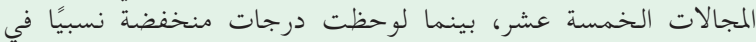

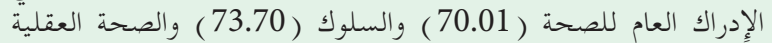

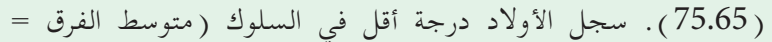

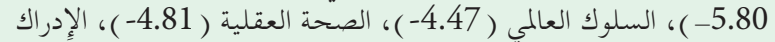

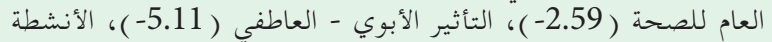

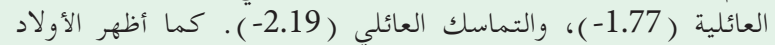

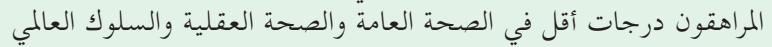

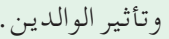

الخلاصة : أظهرت هذه الدراسة درجات مرضية بشكل عام لنوعية حياة

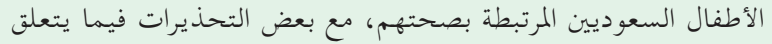

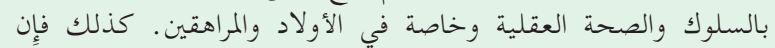

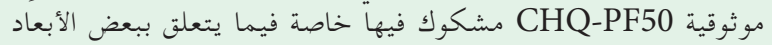
ولأطفال المراهقين.
\end{abstract}

Objectives: To assess the health-related quality of life (HRQOL) of children from a community in Jeddah, Saudi Arabia, excluding those with known chronic illnesses.
Methods: Four schools in Jeddah participated in this cross-sectional study, which was conducted from February 2018 to February 2019. The parents of 5-14 year-old children were surveyed using the validated Arabic version of the Child Health Questionnaire-Parent Form 50 (CHQ-PF50). It consisted of 50 items divided into 15 scales (namely, 11 multi-item and 4 single-item scales) and expressed as scores of 0-100, with higher scores indicating better HRQOL. The levels of HRQOL were analyzed and compared.

Results: The parents of 498 children answered the questionnaire. The mean scores of CHQ-PF50 subscales were relatively high $(>80)$ in 8 out of 15 domains. However, relatively low scores were observed for general health perception (70.01), behavior (73.70), and mental health (75.65). Boys scored lower in behavior (difference of means $=-5.80$ ), global behavior $(-4.47)$, mental health $(-4.81)$, general health perception $(-2.59)$, parental impact-emotional (-5.11), family activities (-1.77), and family cohesion (-2.19). Furthermore, adolescent boys scored lower in global health, mental health, global behavior, and parental impact.

Conclusion: This study showed globally adequate levels of HRQOL among Saudi children, with some limitations in behavior and mental health, especially in boys and adolescents.

Saudi Med J 2019; Vol. 40 (11): 1134-1143 doi: 10.15537/smj.2019.11.24660

From the Pediatric Department, King Abdulaziz University Hospital, Jeddah, Kingdom of Saudi Arabia.

Received 4th October 2019. Accepted 17th October 2019.

Address correspondence and reprint request to: Dr. Wallaa A. Garout, Pediatric Department, King Abdulaziz University Hospital, Jeddah, Kingdom of Saudi Arabia. E-mail: dr.w.garout@gmail.com ORCID ID: https://orcid.org/0000-0001-6729-9092 
Si ince the first introduction of its concept in the 1990 s, health-related quality of life (HRQOL) has gained the attention of the public health community as a significant indicator of somatic outcomes such as morbidity and mortality. ${ }^{1}$ Health-related quality of life $(\mathrm{QoL})$ is a multidimensional measure of a person's functions in life and his/her subjective feelings about the physical, mental, psychological, and social domains of life due to the effects of a medical condition or treatment. ${ }^{2}$ In the above mentioned definition, the term "functions" indicates the ability of an individual to perform some predefined activities. ${ }^{3}$ The combined measures of the different domains of life provide a comprehensive assessment of the perceived burden of preventable diseases, disabilities, and injuries. ${ }^{4}$

By focusing on children and adolescent populations, HRQOL can be affected by several factors. Evidence has shown that bad health conditions (namely, the frequency of health problems and the number of healthcare visits) may directly or indirectly influence the HRQOL. ${ }^{5}$ Furthermore, the impact of specific demographic and socioeconomic factors such as age, gender, parental education, and family's economic level on the QoL of this age group may be apparent. ${ }^{6,7}$ Moreover, multiple religious and ethnic factors may play a considerable role. ${ }^{8,9}$ Therefore, there is a need to assess the impact of these factors.

The classically used tools for quantifying the potential determinants of HRQOL of children and adolescents include the Pediatric Quality of Life Inventory, ${ }^{10}$ the DISABKIDS questionnaire, ${ }^{11}$ and the Child Health Questionnaire (CHQ). ${ }^{12}$ These tools might target specific populations with a stable health condition or might be generic (to universally assess patients regardless of their health status). Specifically, the CHQ tool was initially developed in 1996 by Landgraf et al, ${ }^{13}$ and subsequently validated in $2004,{ }^{14}$ to investigate the levels of HRQOL of 5-18 year-old participants with sickle-cell disease. The CHQ-Parent Form (PF) is a generic tool measuring parent-reported physical and psychological factors in 5-18 year-old children and adolescents. ${ }^{15}$ Several forms are available based on the number of items. However, 2 forms are well known, namely, the 28-item (CHQ-PF28) and 50-item (CHQ-PF50) surveys.

Children and adolescents represent a considerable proportion of the overall population in Saudi Arabia,

Disclosure. Authors have no conflict of interests, and the work was not supported or funded by any drug company. which stresses the relevance of assessing health status and wellbeing among this population group. The latest population statistics from 2018 indicate that there are $5,431,949$ children (5-14 years of age) in Saudi Arabia, including males and females, representing $16.3 \%$ of the total population. ${ }^{16}$ Besides, HRQOL-related factors may be perceived differently by children and their parents in different communities. Therefore, we aimed to assess the QoL among apparently healthy school-age children in Jeddah, Saudi Arabia. Also, we investigated variance in the QoL across gender and age.

Methods. This cross-sectional study was carried out among primary and middle school children in Jeddah, Saudi Arabia, from February 2018 to February 2019. Inclusion criteria applied for both gender, 5-14-yearold healthy children, who are attending government schools in Jeddah. We excluded children with known primary diseases and those with disabilities. Permission to conduct this study was granted by the Biomedical Ethics Committee of King Abdulaziz University (Reference No 65-18), Jeddah, Saudi Arabia.

Sample size was calculated to detect a mean (SD) score $=93.26$ (12.03) in General Health subscale of CHQ-PF50, as reported among a group of healthy controls $(n=69),{ }^{17}$ with $3 \%$ confidence width and $95 \%$ confidence level. The calculated sample size $(n=248)$ was doubled assuming 50\% of nonresponse. Thus, the target sample size was 496, approximately 500 .

A stratified sampling technique was used to include 2 primary and 2 middle schools out of the 12661 primary schools and 7577 middle schools in Jeddah. Then, convenience sampling was used to include all eligible children from all selected schools until reaching the target sample size.

Study tools and scoring system. This study used the Arabic-translated version of the CHQ-PF50. The CHQ is a generic health-related QoL questionnaire, which was developed to assess the physical and psychological well-being of children of 5 years of age and older. Several versions of $\mathrm{CHQ}$ exist, which mainly differ by the respondent and length of the questionnaire (number of items). The CHQ-PF50, which targets parents, consists of 50 items divided into 15 scales, 11 multi- and 4 single-item scales. Multi-item scales include: physical functioning (PF, 6 items); role/ social limitations-physical (REB, 2 items); role/social limitations-emotional/behavioral (RP, 3 items); bodily pain/discomfort (BP, 2 items); behavior (BE, 5 items); mental health (MH, 5 items); self-esteem (SE, 6 items); general health perceptions (GH, 5 items); parent impact-emotion (PE,3 items); parent impact-time (PT, 
3 items); and family activities (FA, 6 items). Single-item scales include global health (GGH); global behavior (GBE); family cohesion (FC); and change in health $(\mathrm{CH}) .{ }^{13}$ All items are designed as Likert-type scales, enabling the calculation of a 0-100 score for each scale; with the exception of the change in health $(\mathrm{CH})$ scale, which is scored from 1 to 5 . In this study, the calculation method conformed to guidelines provided in the Scoring and Interpretation Manual. ${ }^{15}$

Early psychometric analysis of the CHQ-PF50 reported good performance of the tool including discriminant and construct validity and reliability, which were measured in different ethnic groups and clinical contexts. ${ }^{18-22}$

Data collection technique. The parents of children were questioned using the validated Arabic version of CHQ-PF50, Saudi Arabia Edition. It was provided by and used under the authorization of the Licensing Department of the Health Act CHQ Inc. [www. healthactchq.com].

Statistical analysis. Statistical analysis performed with the Statistical Package for Social Sciences version 21.0 for Windows (SPSS Inc., Chicago, IL, USA). Descriptive statistics were used to summarize the scores of 15 CHQ-PF50 subscales in the study sample by calculating medians, means, 95\% confidence interval (95\%CI), and standard deviations (SD). All CHQ-PF50 subscale scores were analyzed for normal distribution using the Kolmogorov-Smirnov and Shapiro-Wilk tests. Bivariate correlation was carried out to analyze the correlation between each pair of CHQ-PF subscales; results were presented as Pearson's correlation coefficient (r) with the corresponding level of statistical significance. The association of QoL dimensions with gender was analyzed using both parametric (independent t-test) and nonparametric (Mann-Whitney U test) tests; results are presented as a mean (SD) and difference of mean ( $\Delta$ mean), with the corresponding level of significance for each test. The association of CHQ with age was analyzed by comparing the subscale scores between all age groups using both parametric (one-way analysis of variance) and nonparametric (Kruskal-Wallis) tests; results were presented as means with the corresponding level of significance. A $p$-value of $<0.05$ was considered to reject the null hypothesis.

Results. Parents of 498 children responded to the questionnaire. The mean (SD) age of children was 8.91 (1.04) and $64.9 \%$ of them were females. The age distribution shows a remarkably high proportion of children aged 9 representing $46.8 \%$ of the study population. Normality testing for age variable showed
Kolmogorov-Smirnov (statistics=0.249, $\quad p<0.001$ ), Shapiro-Wilk (statistics=0.908, $p<0.001$ ), indicating non-normal distribution.

Tool reliability for the study population. Analysis of reliability showed high Cronbach's alpha using both raw $(0.721,50$ items) and transformed, scaled (0.853, 15 items) variables of the questionnaire, indicating globally high reliability of the tool in the study population. Further, reliability was satisfactory and high in majority subscales, except for GH (0.415, 5 items), $\mathrm{MH}(0.591,5$ items), and BE $(0.663,2$ items) where lower Cronbach's alpha value were observed.

Health-related quality of life assessment. The medians, means, 95\%CI of means and standard deviations (SD) of all CHQ-PF50 subscales are presented in Table 1 . These showed relatively high scores $(>80)$ in 8 domains, indicating good QoL among the studied population. However, relatively lower scores were observed for GH (mean=70.01, median=68.33), behavior (mean=73.70, median=75.00), and $\mathrm{MH}$ (mean $=75.65$, median $=80.00)$ scales.

Correlations between CHQ-PF50 subscales. Correlations between the CHQ-PF50 subscales were analyzed and showed 4 moderate-to-strong positive correlations: between PF and both REB ( $r=0.645)$ and $\mathrm{RP}(\mathrm{r}=0.622)$, between the REB limitations subscales $(\mathrm{r}=0.697)$, and between $\mathrm{MH}$ and $\mathrm{BE}(\mathrm{r}=0.628)$. All of the abovementioned correlations were statistically significant. Twelve moderately positive correlations were found, notably family activities with bodily pain $(\mathrm{r}=0406), \mathrm{BE}(\mathrm{r}=0.450), \mathrm{MH}(\mathrm{r}=0.415)$, and $\mathrm{GH}(\mathrm{r}=0.444)$; while family cohesion was likely to be more dependent on GBE ( $r=0.480)$ and self-esteem $(\mathrm{r}=0.444)$. It is worth noting that the GGH and GH were moderately correlated ( $\mathrm{r}=0.540)$ (Table 2).

Health-related quality of life by gender. Statistically significant gender differences were observed in 6 out of 15 domains including $\mathrm{BE}(\Delta$ mean $=-5.80, p<0.001)$, GBE (-4.47, $p<0.001), \mathrm{MH}(-4.81, p<0.001), \mathrm{GH}$ $(-2.59, p=0.029)$, PE $(-5.11, p=0.004)$, FA $(-1.77$, $p=0.011)$, and FC $(-2.19, p=0.019)$; the scores of the males were lower than those of the females in all 6 dimensions. No statistically significant difference was observed in the other domains, as shown in Table 3.

Health-related quality of life by age. The association of QoL with age was analyzed for every CHQ-PF50 subscale using both parametric and nonparametric tests, and the results are depicted in Table 4. The most statistically remarkable differences lied in REB, GBE, and $\mathrm{GH}$, where both parametric and nonparametric tests were significant. Otherwise, all remaining domains showed statistically significant differences in either tests except BP which showed no statistically significant 
Child health questionnaire in Saudi children ... Albokhari et al

Table 1 - Health-related quality of life of children.

\begin{tabular}{lccccccc}
\hline Subscale & $\begin{array}{c}\text { No. } \\
\text { items }\end{array}$ & $\begin{array}{c}\text { Max. } \\
\text { score }\end{array}$ & Median & Mean & $\begin{array}{c}95 \% \text { confidence } \\
\text { interval }\end{array}$ & SD \\
\hline Global health & 1 & 100 & 100.00 & 88.94 & 87.40 & 90.49 & 17.48 \\
Physical functioning & 6 & 100 & 94.44 & 85.76 & 83.68 & 87.85 & 22.51 \\
$\begin{array}{l}\text { Role/social limitations- } \\
\text { emotional/behavioral }\end{array}$ & 3 & 100 & 100.00 & 86.28 & 84.13 & 88.44 & 23.24 \\
Role/social limitations-physical & 2 & 100 & 100.00 & 86.96 & 84.76 & 89.17 & 23.81 \\
Bodily pain/discomfort & 2 & 100 & 80.00 & 81.02 & 79.21 & 82.84 & 19.60 \\
Behavior & 5 & 100 & 75.00 & 73.70 & 72.18 & 75.22 & 16.39 \\
Global behavior & 1 & 100 & 100.00 & 87.94 & 86.31 & 89.58 & 17.65 \\
Mental health & 5 & 100 & 80.00 & 75.56 & 74.14 & 76.99 & 15.37 \\
Self esteem & 6 & 100 & 91.67 & 88.96 & 87.83 & 90.10 & 12.21 \\
General health perceptions & 5 & 100 & 68.33 & 70.01 & 68.55 & 71.47 & 15.78 \\
Change in health & 1 & 5 & 4.00 & 3.95 & 3.86 & 4.04 & 0.97 \\
Parental impact-emotional & 3 & 100 & 83.33 & 76.70 & 74.52 & 78.89 & 23.57 \\
Parental impact-time & 3 & 100 & 88.89 & 79.72 & 77.24 & 82.20 & 26.77 \\
Family activities & 6 & 100 & 79.17 & 78.17 & 76.47 & 79.88 & 18.44 \\
Family cohesion & 1 & 100 & 85.00 & 81.57 & 79.57 & 83.56 & 21.50 \\
\hline
\end{tabular}

Table 2 - Bivariate correlations between Child Health Questionnaire (CHQ)-PF50 subscales.

\begin{tabular}{|c|c|c|c|c|c|c|c|c|c|c|c|c|c|c|}
\hline Subscale & GGH & PF & REB & $\mathrm{RP}$ & BP & $\mathrm{BE}$ & GBE & MH & SE & GH & PE & PT & FA & FC \\
\hline Global health (GGH) & - & - & - & - & - & - & - & - & - & - & - & - & - & - \\
\hline Physical functioning (PF) & $0.221^{*}$ & - & - & - & - & - & - & - & - & - & - & - & - & - \\
\hline $\begin{array}{l}\text { Role/social limitations - } \\
\text { emotional/behavioral (REB) }\end{array}$ & $0.204^{*}$ & $0.645^{*}$ & - & - & - & - & - & - & - & - & - & - & - & - \\
\hline $\begin{array}{l}\text { Role/social limitations - } \\
\text { physical (RP) }\end{array}$ & $0.222^{*}$ & $0.622^{*}$ & $0.697^{*}$ & - & - & - & - & - & - & - & - & - & - & - \\
\hline Bodily pain/discomfort (BP) & $0.230^{*}$ & $0.347^{*}$ & $0.334^{*}$ & $0.368^{*}$ & - & - & - & - & - & - & - & - & - & - \\
\hline Behavior (BE) & $0.282^{*}$ & $0.216^{*}$ & $0.292^{*}$ & $0.234^{*}$ & $0.340^{*}$ & - & - & - & - & - & - & - & - & - \\
\hline Global behavior (GBE) & $0.447^{*}$ & $0.193^{*}$ & $0.228^{*}$ & $0.240^{*}$ & $0.112^{*}$ & $0.459^{*}$ & - & - & - & - & - & - & - & - \\
\hline Mental health (MH) & $0.221^{*}$ & $0.249^{*}$ & $0.290^{*}$ & $0.259^{*}$ & $0.389^{*}$ & $0.628^{*}$ & $0.384^{*}$ & - & - & - & - & - & - & - \\
\hline Self esteem (SE) & $0.317^{*}$ & $0.183^{*}$ & $0.243^{*}$ & $0.161^{*}$ & $0.159^{*}$ & $0.377^{*}$ & $0.414^{*}$ & $0.396^{*}$ & - & - & - & - & - & - \\
\hline $\begin{array}{l}\text { General health perceptions } \\
\text { (GH) }\end{array}$ & $0.540^{*}$ & $0.328^{*}$ & $0.294^{*}$ & $0.348^{*}$ & $0.392^{*}$ & $0.359^{*}$ & $0.365^{*}$ & $0.309^{*}$ & $0.301^{*}$ & - & - & - & - & - \\
\hline $\begin{array}{l}\text { Parental impact-emotional } \\
\text { (PE) }\end{array}$ & $0.223^{*}$ & $0.182^{*}$ & 0.362 & $0.291^{*}$ & $0.373^{*}$ & 0.442 & $0.320^{*}$ & $0.381^{*}$ & $0.359^{*}$ & $0.345^{*}$ & - & - & - & - \\
\hline Parental impact-time (PT) & $0.152^{*}$ & $0.396^{*}$ & 0.394 & $0.392^{*}$ & $0.360^{*}$ & $0.314^{*}$ & $0.202^{*}$ & $0.271^{*}$ & $0.240^{*}$ & $0.343^{*}$ & $0.437^{*}$ & - & - & - \\
\hline Family activities (FA) & $0.200^{*}$ & $0.338^{*}$ & 0.325 & $0.313^{*}$ & $0.406^{*}$ & $0.450^{*}$ & $0.282^{*}$ & $0.415^{*}$ & $0.235^{*}$ & $0.444^{*}$ & $0.387^{*}$ & $0.521^{*}$ & - & - \\
\hline Family cohesion (FC) & $0.362^{*}$ & 0.076 & 0.081 & 0.038 & 0.050 & $0.365^{*}$ & $0.480^{*}$ & $0.307^{*}$ & $0.444^{*}$ & $0.253^{*}$ & $0.281^{*}$ & $0.134^{*}$ & $0.327^{*}$ & - \\
\hline
\end{tabular}


Table 3 - Health-related quality of life by gender of children.

\begin{tabular}{|c|c|c|c|c|c|c|}
\hline \multirow[t]{2}{*}{ Subscale } & \multicolumn{2}{|c|}{ Male } & \multicolumn{2}{|c|}{ Female } & \multirow[t]{2}{*}{$\Delta$ means } & \multirow[t]{2}{*}{ P-value } \\
\hline & Mean & SD & Mean & SD & & \\
\hline Global health & 89.17 & 18.03 & 92.10 & 14.43 & -2.91 & 0.101 \\
\hline Physical functioning & 86.40 & 22.13 & 86.26 & 23.49 & +1.13 & 0.956 \\
\hline Role/social limitations - emotional/behavioral & 82.93 & 25.74 & 88.27 & 23.51 & -1.86 & 0.051 \\
\hline Role/social limitations - physical & 85.25 & 26.43 & 89.97 & 22.56 & -1.96 & 0.082 \\
\hline Bodily pain/discomfort & 78.05 & 21.14 & 81.69 & 18.66 & -2.77 & 0.098 \\
\hline Behavior & 69.26 & 15.94 & 78.56 & 15.23 & -5.80 & $<0.001^{*}$ \\
\hline Global behavior & 85.24 & 19.68 & 92.77 & 12.22 & -4.47 & $<0.001^{*}$ \\
\hline Mental health & 71.83 & 16.13 & 78.81 & 14.41 & -4.81 & $<0.001^{*}$ \\
\hline Self esteem & 89.52 & 12.84 & 91.09 & 10.42 & -1.17 & 0.216 \\
\hline General health perceptions & 68.97 & 15.60 & 72.85 & 15.89 & -2.59 & $0.029^{*}$ \\
\hline Change in health & 4.18 & 0.93 & 4.08 & 0.98 & -0.01 & 0.373 \\
\hline Parental impact - emotional & 73.97 & 23.41 & 81.34 & 22.45 & -5.11 & $0.004^{*}$ \\
\hline Parental impact - time & 79.10 & 24.75 & 82.20 & 27.64 & +0.55 & 0.308 \\
\hline Family activities & 75.61 & 19.76 & 81.03 & 18.11 & -1.77 & $0.011^{*}$ \\
\hline Family cohesion & 81.20 & 22.89 & 86.41 & 17.45 & -2.91 & $0.019^{*}$ \\
\hline
\end{tabular}

Table 4 - Health-related quality of life by age and by Child Health Questionnaire (CHQ)-PF50 subscale.

\begin{tabular}{|c|c|c|c|c|c|c|c|c|c|c|c|c|c|c|c|c|}
\hline \multirow{2}{*}{$\begin{array}{l}\text { Age category } \\
\text { (years) }\end{array}$} & \multirow[t]{2}{*}{$\mathrm{N}$} & \multicolumn{15}{|c|}{ CHQ-PF50 subscale (mean score) } \\
\hline & & GGH & PF & REB & $\mathrm{RP}$ & $\mathrm{BP}$ & $\mathrm{BE}$ & GBE & $\mathrm{MH}$ & SE & GH & $\mathrm{CH}$ & PE & PT & FA & FC \\
\hline 5 & -30 & 87.24 & 92.04 & 87.41 & 88.33 & 76.00 & 76.17 & 89.50 & 74.33 & 92.41 & 65.37 & 4.21 & 75.86 & 81.61 & 75.86 & 86.38 \\
\hline 6 & -40 & 90.26 & 87.22 & 81.39 & 85.90 & 84.36 & 71.63 & 88.21 & 74.00 & 91.88 & 71.90 & 3.88 & 77.35 & 80.34 & 78.82 & 85.77 \\
\hline 7 & -39 & 94.05 & 91.08 & 93.16 & 93.16 & 83.85 & 74.61 & 90.00 & 73.97 & 92.41 & 71.67 & 4.23 & 75.43 & 80.70 & 77.37 & 82.37 \\
\hline 8 & -40 & 92.38 & 87.81 & 85.28 & 88.33 & 79.50 & 71.88 & 87.95 & 76.78 & 85.94 & 71.59 & 4.08 & 75.64 & 74.36 & 76.50 & 87.37 \\
\hline 9 & -232 & 85.45 & 86.45 & 87.28 & 86.20 & 81.20 & 73.25 & 84.18 & 75.34 & 88.08 & 68.21 & 3.75 & 76.65 & 80.98 & 78.67 & 77.57 \\
\hline 10 & -29 & 90.17 & 79.33 & 84.81 & 80.95 & 77.00 & 73.17 & 92.33 & 78.79 & 92.19 & 72.47 & 4.23 & 79.72 & 73.18 & 71.11 & 79.83 \\
\hline 11 & -25 & 95.40 & 92.87 & 94.91 & 95.14 & 85.00 & 80.00 & 93.80 & 79.40 & 92.33 & 77.30 & 3.96 & 88.00 & 91.20 & 86.63 & 85.00 \\
\hline 12 & -28 & 93.21 & 79.92 & 77.38 & 78.57 & 79.64 & 75.18 & 89.46 & 77.54 & 87.65 & 71.50 & 4.14 & 73.51 & 74.60 & 78.33 & 87.78 \\
\hline 13 & -18 & 95.00 & 92.59 & 97.53 & 99.07 & 88.33 & 82.50 & 98.24 & 81.11 & 85.46 & 77.41 & 4.17 & 85.19 & 83.95 & 86.57 & 83.33 \\
\hline 14 & -15 & 92.67 & 54.07 & 60.37 & 73.33 & 72.67 & 80.33 & 92.86 & 74.33 & 81.67 & 66.56 & 4.13 & 74.44 & 72.59 & 71.11 & 84.00 \\
\hline \multicolumn{17}{|l|}{ P-value } \\
\hline Par. & & $0.007^{*}$ & $<0.001^{*}$ & $<0.001^{*}$ & $0.015^{*}$ & 0.249 & 0.174 & $0.009^{*}$ & 0.674 & $0.005^{*}$ & $0.031^{*}$ & $0.012^{*}$ & 0.411 & 0.269 & 0.054 & $0.047^{*}$ \\
\hline Npar. & & 0.424 & 0.643 & $0.007^{*}$ & 0.054 & 0.122 & $<0.001^{*}$ & $<0.001^{*}$ & $<0.001^{*}$ & 0.480 & $0.036^{*}$ & 0.423 & $0.001^{*}$ & $0.042^{*}$ & $0.009^{*}$ & 0.063 \\
\hline $\begin{array}{l}\text { The values ar } \\
\text { way ANOVA } \\
\text { REB - Role/ } \\
\text { Global Beha }\end{array}$ & $100 \mathrm{C}$ & GBE), $N$ & HH - Men & In & h, SE - & Este & $\mathrm{m}, \mathrm{GH}-$ & General $\mathrm{H}$ & $\begin{array}{l}\text { cions - Ph } \\
\text { Health Pe }\end{array}$ & rysical, & $\begin{array}{l}\text { icance } \\
\text { - Bod - } \\
\text { PE - P } \\
\text { esion }\end{array}$ & Pain/I & pcomf & $\begin{array}{l}\text { ig paran } \\
\text { - Physic } \\
\text { t, BE - } \\
\text { motiona }\end{array}$ & $\begin{array}{l}\text { etric tes } \\
1 \text { Funct } \\
\text { ehavior, } \\
\text { PT - P }\end{array}$ & $\begin{array}{l}\text { (One } \\
\text { ning, } \\
\text { GBI - } \\
\text { ental }\end{array}$ \\
\hline
\end{tabular}


difference. The characterization of these differences showed 3 decline points for several CHQ domains at the ages of 5, 9, and 14 years. Most remarkably, the 14-year-old category exhibited considerable decline in PF, REB, and RP domains.

Health-related quality of life by gender and age group. Figure 1 presents gender differences by age group for all scale scores. Significant gender differences were observed in older and medium age (9-11 years) groups, where boys had lower scores than girls in several domains depending on age class. Younger boys (5-6 years) showed lower scores in $\mathrm{BE}, \mathrm{GBE}$, and $\mathrm{MH}$ compared to girls from the same age group. Medium age boys (9-10 years) showed lower scores in bodily pain, BE, MH, PE, FA, and FC. Older boys (12-14 years) showed lower scores in GGH, MH, GBE, PT, and GH.

Discussion. This survey-based study assessed the quality of life of healthy school-age children in the western province of Saudi Arabia using an internationally validated parents-reported tool. The study showed high scores of HRQOL in majority of the explored domains, which indicates an acceptable health status among the studied population. Relatively lower levels of health were observed for behavior, mental health, and general health perception. The questionnaire scores correlated in a moderate-to-fair fashion. Further, the questionnaire showed globally good internal consistency in the studied population, which indicates the reliability of the findings.

Parents-reported information regarding the QoL of their children is a worldwide acceptable and commonly used method, clinically, which showed fair agreement with children's self-reported results. ${ }^{23}$ In general, HRQOL and other models of QoL underscore the subjective nature of the assessment. The degree of satisfaction with the personal health status is the cornerstone of HRQOL as compared to the ideal health status. It differs from the QoL evaluation by a physician, which is objective, by reporting the patient's own subjective experience. ${ }^{24}$ However, it is possible to describe the personal health in an apparently-healthy sample the population by exploring different HRQOL domains, which may reflect the effect of specific unknown disease groups. ${ }^{25}$ This approach can be supported by the HRQOL criteria defined by the World Health Organization, which include the individual's perception of his/her position in life by reference to the standards, concerns, goals, and expectations of the culture and value systems where the person lives. ${ }^{26}$ Moreover, the assessment of HRQOL should include not only the negative aspects of QoL but also the positive components of personal experience, such as ease of adaptability, hope, and satisfaction. ${ }^{24}$ However, very few studies in literature investigated HRQOL among healthy children; as most studies focused on the impact of chronic diseases or disabilities on HRQOL and included healthy, or apparently healthy, individuals as controls for afflicted ones. Thus, the discussion part of this article will mainly focus on interpreting the findings of this study and conclude by suggesting some clinical and research applications at the individual and public health levels.

An Iranian study compared the HRQOL of obese children and those afflicted with a set of chronic diseases with healthy ones. Authors used another scale, namely the Pediatric Quality of Life Inventory ${ }^{\mathrm{TM}}$ Version 4.0 (PedsQLTM 4.0), which comprises 4 subscales including physical, emotional, social and school functioning, each expressed as 0-to-100 score. By focusing on healthy group, comparison with our study reveal fairly comparable findings regarding physical functioning and social functioning, where scores ranged between $80-95$ out of $100 .{ }^{27}$ Another study by PinhasHamiel investigated the association of obesity with QoL by comparing apparently healthy normal weight versus obese children by means of the PedsQLTM 4.0, using both child- and parent-reported versions. Normal weight children showed $>80$ mean scores in physical, social and school functioning, whereas emotional functioning showed mean score of 74.1 and 73.2 in child- and parent-reported assessments; ${ }^{28}$ which is fairly comparable to findings from our study. Further, both studies demonstrated a significant association of HRQOL with weight, as obese children had significantly lower scores in all 4 dimensions. Although weight factor has not been investigated in our study, such observations indicate that children's psychological wellbeing and behavior is sensitive even to minor disturbances and may be significantly affected by non-pathological conditions such as overweight and obesity. Such observations highlight the importance for children to grow up in a healthy psychosocial and physical environment to enable adequate psychomotor development and prevent eventual psychosocial problems in adolescence and adulthood. Therefore, home environment and the role of parents have been emphasized in promoting healthy dietary and lifestyle habits and limiting toxic factors such as energy dense foods, sedentary behaviors, and screens..$^{29,30}$ Studies in this field suggest that a balance point between parental restriction and permissiveness should be maintained to prevent excessive behaviors that may result either from frustration or unhealthy habits. ${ }^{31-33}$ 
Child health questionnaire in Saudi children ... Albokhari et al
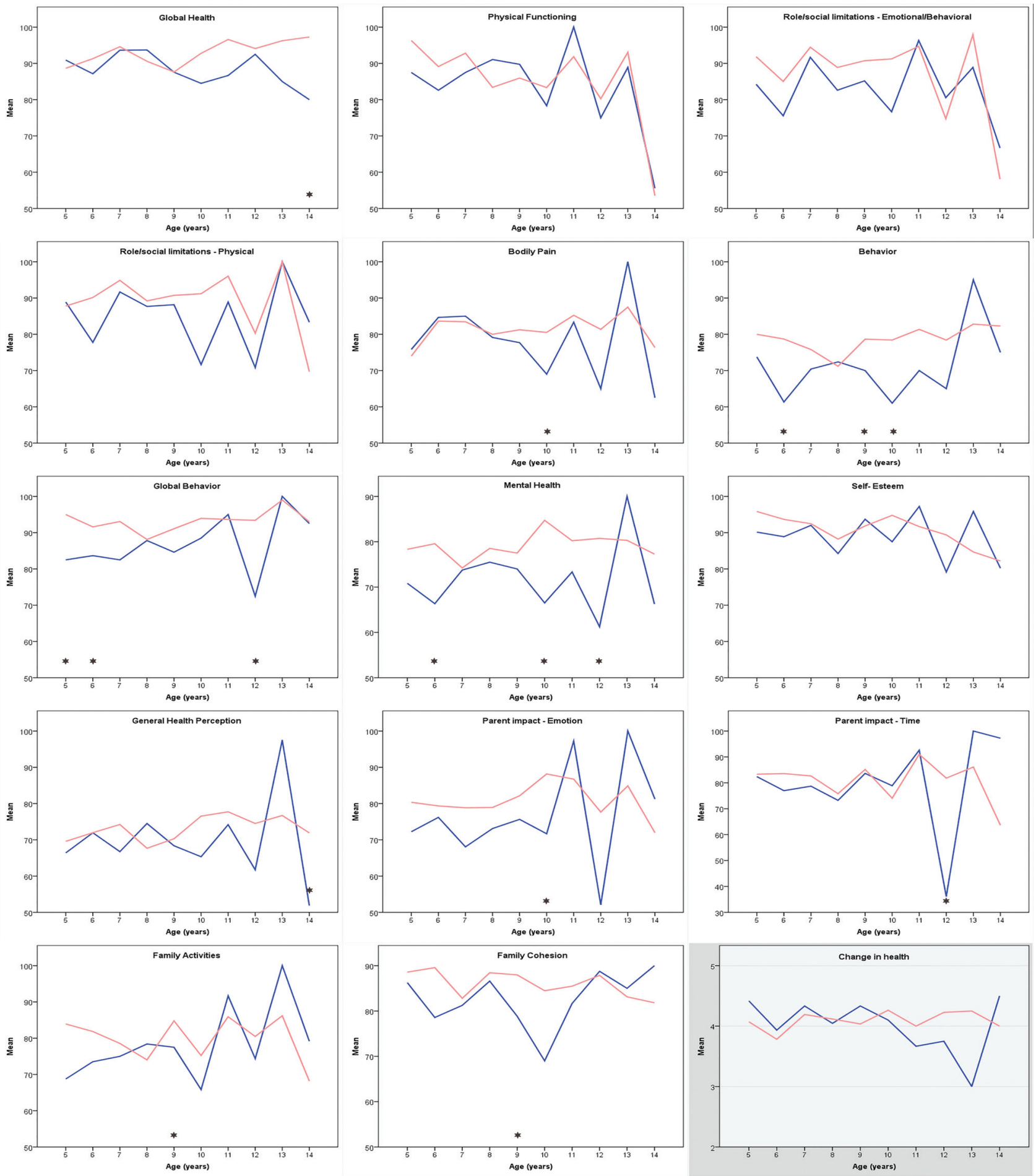

Figure 1 - Quality of life dimensions by age and gender of children Error. *Statistically significant difference between girls (pink curve) and boys (blue curve) for the given age group and dimension. 
In the present study, statistically significant differences were found between the 2 genders concerning 6 life domains; on the other hand, the mean differences ranged between 1.77 to 5.80 on a $0-100$ scale, which may not be clinically significant. However, it is worth noting that 5 of the 6 concerned domains have relationship with psychological and behavioral wellbeing with parallel impact on parents and family wellbeing. In the previously cited Iranian study, similar observation can be deduced regarding emotional functioning where boys (mean score=77.0) had lower scores compared to girls (81.5), although they achieved higher physical (90.5 versus 88.0) and social (90.5 versus 87.1) functioning scores, respectively; however, authors did not analyze the statistical significance of this fluctuation being not the scope of their study. ${ }^{27}$ Other authors of an Iranian study reported significant gender effect on the QOL among children afflicted with epilepsy, which may denote adjacent sociocultural factors inducing discrepancy between girls and boys. ${ }^{34}$

More remarkably, older and medium ages were crucial, especially for boys where behavior and psychological health was relatively disturbed associating impact on parents and family functioning. Furthermore, adolescence period was likely to be the most affected in both genders regarding physical functioning, emotional and behavioral dimensions as well as family impact with corresponding scores dropping down to 60. Comparatively, a study from Pakistan explored HRQOL among schooled adolescents using the KINDL questionnaire, which comprises 6 dimensions including physical health, emotional health, self-esteem, family functioning, social functioning and school functioning. Authors reported relatively higher scores, with mean 0 to 100 scaled scores ranging between 77.8 for self-esteem to 98.2 in family functioning, notably emotional health which was scored as high as 96.7.35 These findings fall relatively higher than ranges reported in our study among the adolescent population.

This open the gates to several interpretations and calls for further exploring eventual gender- and age-specific factors that may interfere with psychological health and psychomotor development of children such as home environment, school factors, smart devices usage, sleep disturbance, physical activity, extra-school activities, socialization, role model, so forth. A systematic review by Wu et $\mathrm{al}^{36}$ including 21 cross-sectional, 6 longitudinal, 3 school-based interventional studies, as well as one mixed design study, demonstrated a significant positive relationship of children and adolescents' HRQOL with the level of physical activity and a negative relationship with sedentary behavior, both in a dose-dependent fashion. Therefore, interventions to increase physical activity and reduce sedentary habits are increasingly advocated among children, especially in preschools where these reduce health inequities notably among socioeconomically disadvantaged populations..$^{37,38}$ In another systematic review, $\mathrm{Wu}$ et $\mathrm{al}^{39}$ explored the effect of diet quality and dietary habits on HRQOL among children and adolescents and concluded to a dose-dependent effect of the quality of diet on HRQOL involving several domains such physical and emotional functioning, psychological wellbeing and school achievement. Among major environmental factors associated with children's HRQOL is the family socioeconomic status, ${ }^{40}$ notably parents' educational level that showed significant association with several life domains and further explained the variance in parent-assessed HRQOL. ${ }^{41}$ Another modern determinant of child's health is the screen time and usage of smart devices, which is unanimously evidenced to disturb behavior and induce negative effect on children's physical and mental health as well as on their psychomotor development. A range of children's health indicators are impacted by screen usage such as physical activity and weight, self-esteem, prosocial behavior, school achievement, depression and anxiety, ${ }^{42,43}$ It is crucial to explore these factors among healthy children in a screening and preventive approach and to raise awareness among parents and schooled children about the healthy and unhealthy lifestyles.

On the other hand, the observed gender and age fluctuations should be interpreted with caution especially in case of parent-reported evaluation as it may entail a significant amount of subjectivity or be biased by the parent-child relationship that may be impaired in adolescence. This hypothesis is supported by the notable lack of internal consistency observed in behavior, mental health and general health perception scales; while all these domains were the most significantly impaired in the total population, especially in adolescent boys. This should question the reliability of the CHQ-PF50 in its original form when used for this age category of Saudi children. Previously, a revised version of the WHO Quality of life questionnaire (WHOQOLBREF) demonstrated superior performance in term of reliability among Indian adolescents compared to PedsQL. ${ }^{8}$ This highlights the need for such tools to be adapted to the local cultures and be as specific as possible to the subpopulations, in a way to improve their reliability.

Study limitations. The major limitation of this study is the failure to explore other sociodemographic 
factors and confounders of HRQOL such as family economic status, parents' educational level, number of children, and parent's marital and professional status; in addition to eventual correlations of the findings with school performance, which is not explored by the used questionnaire. Sociodemographic factors and school performance data were omitted from this survey in the interest of simplicity for parents and to improve the response rate. Another major limitation is the nonconsideration of age factor in sampling, which yielded a biased age distribution with a peak frequency of 9-year old children and low inclusion of adolescent age one (13-14 years old). Further, investigating parent-child relation would have made a major contribution in stating about the reliability of the results.

In conclusion, parents' survey showed globally adequate levels of HRQOL among primary and middle school children in the western province of Saudi Arabia, with some caveats regarding behavior and mental health dimensions, especially in adolescents.

Several gender variances were observed notably in behavior, emotion and mental health where boys totalized lower scores than girls, associating a relative impact on parents and family functioning. These differences across gender and age classes suggest the existence of age- and gender-specific factors of HRQOL that should be further explored in a screening and preventive approach. On the other hand, the reliability of the parents-reported information regarding these specific dimensions and for these specific age classes may be disputed, by considering the relatively lower psychometric performance of the tool in these dimensions.

The interpretation of these findings highlights the urgent need for comprehensive investigation of factors that may interfere with the physical and psychological health and wellbeing and psychomotor development of children, by using tools that are more adapted to the local culture and that are as specific as possible to each age group. Particular attention should be paid to modifiable risk factors, which are subject to preventive strategies and awareness-raising campaigns among parents and children.

Acknowledgment. We sincerely thank the participating schools of Jeddah, Saudi Arabia. Also, we would like to thank Falcon Scientific Editing for English language editing of this study.

\section{References}

1. Schipper H. Quality of life: principles of the clinical paradigm. J Psychosoc Oncol 1990; 8: 171-185.
2. Karimi M, Brazier J. Health, Health-Related Quality of Life, and Quality of Life: What is the Difference? Pharmacoeconomics 2016; 34: 645-649.

3. Yin S, Njai R, Barker L, Siegel PZ, Liao Y. Summarizing healthrelated quality of life (HRQOL): development and testing of a one-factor model. Popul Health Metr 2016; 14: 22.

4. Revicki DA, Kleinman L, Cella D. A history of health-related quality of life outcomes in psychiatry. Dialogues Clin Neurosci 2014; 16: 127-135.

5. Waters E, Davis E, Nicolas C, Wake M, Lo SK. The impact of childhood conditions and concurrent morbidities on child health and well-being. Child Care Health Dev 2008; 34: 418-429.

6. Ravens-Sieberer U, Gosch A, Rajmil L, Erhart M, Bruil J, Power M, et al. The KIDSCREEN-52 quality of life measure for children and adolescents: psychometric results from a crosscultural survey in 13 European countries. Value Health 2008; 11: 645-658.

7. Simon AE, Chan KS, Forrest CB. Assessment of children's health-related quality of life in the United States with a multidimensional index. Pediatrics 2008; 121: e118-e126.

8. Awasthi S, Agnihotri K, Chandra H, Singh U, Thakur S. Assessment of Health-Related Quality of Life in school-going adolescents: validation of PedsQL instrument and comparison with WHOQOL-BREF. Natl Med J India 2012; 25: 74-79.

9. Massad SG, Nieto FJ, Palta M, Smith M, Clark R, Thabet AA. Health-related quality of life of Palestinian preschoolers in the Gaza Strip: a cross-sectional study. BMC Public Health. 2011; 11: 253.

10. Varni JW, Seid M, Rode CA. The PedsQL: measurement model for the pediatric quality of life inventory. Med Care 1999; 37: 126-139.

11. Fayed N, de Camargo OK, Kerr E, Rosenbaum P, Dubey A, Bostan C, et al. Generic patient-reported outcomes in child health research: a review of conceptual content using World Health Organization definitions. Dev Med Child Neurol 2012; 54: 1085-1095.

12. Palermo TM, Schwartz L, Drotar D, McGowan K. Parental report of health-related quality of life in children with sickle cell disease. J Behav Med 2002; 25: 269-283.

13. Landgraf J, Abetz L, Ware J. Child Health Questionnaire (CHQ): A user's manual: Health Institute. Massachusetts: New England Medical Center; 1996.

14. Panepinto JA, O’Mahar KM, DeBaun MR, Rennie KM, Scott JP. Validity of the child health questionnaire for use in children with sickle cell disease. J Pediatr Hematol Oncol 2004; 26 : 574-578.

15. HealthActCHQ.com. CHQ: Child Health Questionnaire ${ }^{\text {TM }}$ Boston (MA): HealthActCHQ; 2019 [cited 2019 March 01]. Available from: https://www.healthactchq.com/survey/chq.

16. General Authority for Statistics. Saudi population 2018Population by Single Age, Nationality (Saudi/Non-Saudi) and Gender. Saudi Arabia (KSA): General Authority for Statistics; 2018 [cited 2019 March 01]. Available from: https://www.stats. gov.sa/sites/all/modules/pubdlcnt/pubdlcnt.php?file=https:// www.stats.gov.sa/sites/default/files/population_2018. xlsx\&nid=21456.

17. Silva CH, Silva TE, Morales NM, Fernandes KP, Pinto RM. Quality of life in children and adolescents with allergic rhinitis. Braz J Otorhinolaryngol 2009; 75: 642-649. 
18. Waters E, Salmon L, Wake M. The parent-form Child Health Questionnaire in Australia: comparison of reliability, validity, structure, and norms. J Pediatr Psychol 2000; 25: 381-391.

19. Raat H, Bonsel GJ, Essink-Bot ML, Landgraf JM, Gemke RJ. Reliability and validity of comprehensive health status measures in children: The Child Health Questionnaire in relation to the Health Utilities Index. J Clin Epidemiol 2002; 55: 67-76.

20. McCullough N, Parkes J, White-Koning M, Beckung E, Colver A. Reliability and validity of the Child Health QuestionnairePF-50 for European children with cerebral palsy. J Pediatr Psychol 2009; 34: 41-50.

21. Ng JY, Landgraf JM, Chiu CS, Cheng NL, Cheung YF, Preliminary evidence on the measurement properties of the Chinese version of the Child Health Questionnaire, parent form (CHQ-pF50) and child form (CHQ-CF87). Qual Life Res 2005; 14: 1775-1781.

22. Morales Nde M, Silva CH, Frontarolli AC, Araujo RR, Rangel VO, Pinto RM, et al. Psychometric properties of the initial Brazilian version of the CHQ-PF50 applied to the caregivers of children and adolescents with cerebral palsy. Qual Life Res 2007; 16: 437-444.

23. Batalha LMC, Fernandes AM, Campos Cd. Quality of life among children with cancer: agreement between child and parent reports. Escola Anna Nery 2015; 19: 292-296.

24. Sosnowski R, Kulpa M, Zietalewicz U, Wolski JK, Nowakowski $\mathrm{R}$, Bakula $\mathrm{R}$, et al. Basic issues concerning health-related quality of life. Cent European J Urol 2017; 70: 206-211.

25. Bullinger M. Assessing health related quality of life in medicine. An overview over concepts, methods and applications in international research. Restor Neurol Neurosci 2002; 20: 93-101.

26. Department of Mental Health and Substance Abuse (MSD)-World Health Organization. WHOQOL Measuring Quality of Life. Geneva: WHO; 1997 [cited 2019 March 1]. Available from: http://www.who.int/mental_health/media/68. pdf.

27. Jalali-Farahani S, Shojaei FA, Parvin P, Amiri P. Comparison of health-related quality of life (HRQoL) among healthy, obese and chronically ill Iranian children. BMC Public Health 2018; 18: 1337 .

28. Pinhas-Hamiel O, Singer S, Pilpel N, Fradkin A, Modan D, Reichman B. Health-related quality of life among children and adolescents: associations with obesity. Int J Obes (Lond) 2006; 30: 267-272.

29. Bryant MJ, Ward DS, Hales D, Vaughn A, Tabak RG, Stevens J. Reliability and validity of the Healthy Home Survey: a tool to measure factors within homes hypothesized to relate to overweight in children. Int J Behav Nutr Phys Act 2008; 5: 23.

30. Srinivasan S, O'Fallon LR, Dearry A. Creating healthy communities, healthy homes, healthy people: initiating a research agenda on the built environment and public health. Am J Public Health 2003; 93: 1446-1450.
31. Fisher JO, Birch LL. Restricting access to foods and children's eating. Appetite 1999; 32: 405-419.

32. Contento IR, Zybert P, Williams SS. Relationship of cognitive restraint of eating and disinhibition to the quality of food choices of Latina women and their young children. Prev Med 2005; 40: 326-336.

33. Lissau I, Breum L, Sorensen TI. Maternal attitude to sweet eating habits and risk of overweight in offspring: a ten-year prospective population study. Int J Obes Relat Metab Disord 1993; 17: 125-129.

34. Momeni M, Ghanbari A, Bidabadi E, Yousefzadeh-Chabok S. Health-Related Quality of Life and Related Factors in Children and Adolescents With Epilepsy in Iran. J Neurosci Nurs 2015; 47: 340-345.

35. Siddique M, Ayub A, Hussain H. Health related quality of life in school going adolescents of Khyber pakhtun-khwa Pakistan. J Ayub Med Coll Abbottabad 2015; 27: 594-597.

36. Wu XY, Han LH, Zhang JH, Luo S, Hu JW, Sun K. The influence of physical activity, sedentary behavior on healthrelated quality of life among the general population of children and adolescents: A systematic review. PLoS One 2017; 12: e0187668.

37. Pate RR, Brown WH, Pfeiffer KA, Howie EK, Saunders RP, Addy CL, et al. An Intervention to Increase Physical Activity in Children: A Randomized Controlled Trial With 4-Year-Olds in Preschools. Am J Prev Med 2016; 51: 12-22.

38. Vander Ploeg KA, Maximova K, McGavock J, Davis W, Veugelers P. Do school-based physical activity interventions increase or reduce inequalities in health? Soc Sci Med 2014; 112: 80-87.

39. Wu XY, Zhuang LH, Li W, Guo HW, Zhang JH, Zhao YK, et al. The influence of diet quality and dietary behavior on healthrelated quality of life in the general population of children and adolescents: a systematic review and meta-analysis. Qual Life Res 2019; 28: 1989-2015.

40. Rezende BA, Lemos SMA, Medeiros AM. Quality of life and health self-perception in children with poor school performance. Rev Paul Pediatr 2017; 35: 415-421.

41. Ringdal K, Ringdal GI, Olsen HK, Mamen A, Fredriksen PM. Quality of life in primary school children: The Health Oriented Pedagogical Project (HOPP). Scand J Public Health 2018; 46 (21 Suppl): 68-73.

42. Saunders TJ, Vallance JK. Screen Time and Health Indicators Among Children and Youth: Current Evidence, Limitations and Future Directions. Appl Health Econ Health Policy 2017; 15: 323-331.

43. Wu X, Tao S, Zhang S, Zhang Y, Chen K, Yang Y, et al. Impact of screen time on mental health problems progression in youth: a 1-year follow-up study. BMJ Open 2016; 6: e011533. 